\title{
Try this at home?
}

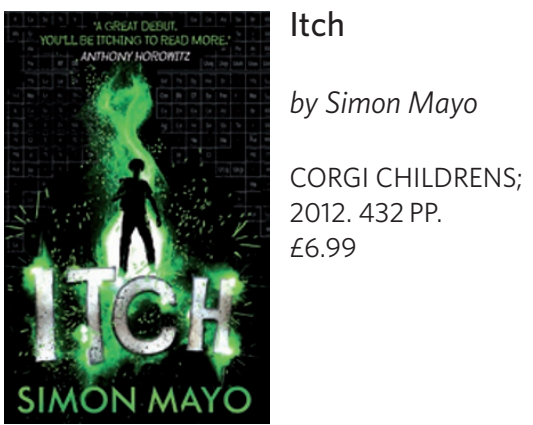

tch derives its name from the fourteenyear-old protagonist who discovers a new element and, as a consequence, gets himself into all kinds of trouble with assassins, shady corporations and malevolent chemistry teachers who'd like to get their hands on it. From the description on the cover of the bedroom explosion in the opening scene and the theme of the book I had nightmare visions of this new element being discovered through some chemical misadventure and immediately prepared to dislike the novel. It actually proved to be a fairly rewarding and scientifically inoffensive read.

Itchingham Lofte is the classic school-age unlikely hero. Lacking any specific sporting talent and desperate not to conform, he chooses to collect elements (although strictly speaking where it suits the plot, he seems to be happy with compounds). "There was, he thought, no point in collecting anything else; this was everything else. It was the catalogue of everything that existed in the universe, stripped down to its 118 basic ingredients."

\section{Itch is pleasingly peppered} with well-researched science and anecdotes ... I even learnt a few things along the way myself.

I immediately identified with Itch. At school I hated anything popular and regularly 'borrowed' chemicals for my own experiments at the bottom of the village field. Many of my friends lost their eyebrows but none had the octogenarian catkins required for sustained combustion that Itch seemed to have at the start of this book before he'd been grinding up phosphorus with match heads as if in a bid for a (depressingly realistic) 1950s Darwin Award.

Mayo writes well for the target age group but the text is in desperate need of editing. The first half is bogged down by irrelevant subplots and exposition of tertiary characters. Relief comes in the form of an extended vomiting episode and a running gag on the state of Itch's eyebrows and there is a genuinely delightful moment where these gags meet.

Mayo clearly has a great love of Cornwall, the setting for the book, whose people and landscape are well rendered. All the classic caricatures of children's fiction are here: the violent grumpy teacher, his dim-witted henchman, the bullies (one of those seemingly irrelevant subplots thrown in to tick a box) and the supportive kind teacher.

There are enough references to SMS, Facebook and YouTube to make the contemporary childhood experience authentic without appearing forced. For those with a smartphone an augmented reality app is even available for download. This app provides an animated version of the front cover, a trailer and an introduction to the book linked from the author's portrait inside the sleeve.

Readers who persevere with the first part of the book are well rewarded.

There is a pleasing early twist and a rapid increase in pace which is sustained almost to the end. Itch uses the elements (and compounds) he has collected like a teenage MacGyver to outwit the adults who underestimate him. This aspect of the character resonated with my own desire as a child to use chemistry to my own ends. I still feel the pangs of disappointment after my dad declined my offer of a film canister of thermite - which I'd suggested he keep in his car in case he ever found it had been clamped.

The biggest surprise this book has to offer is the quality of the science, which almost always falls close enough to the truth to be explained away by suspension of disbelief. Far from my fears of our 'element hunter' discovering the new element through some chemical reaction, he acquires it indirectly from a slag heap.

At the end of the book, Mayo credits his inspiration: the scientists who have appeared on his popular BBC Radio 2 drive-time show. Through Andrea Sella he was introduced to the idea of the "island of stability' and his choice of the atomic number 126 for Itch's new element is consistent with this. A visit from James Lovelock obviously accounts for the (otherwise inexplicable) discussion of Gaia theory halfway through the book.

\section{"It was the catalogue of everything that existed in the universe, stripped down to its 118 basic ingredients."}

Itch is pleasingly peppered with wellresearched science and anecdotes and the credits reveal an extensive backing team of physicists and chemists who've ensured the concepts are fairly solid. I even learnt a few things along the way myself: I was previously unaware of xenon's anaesthetic properties but Itch's use of it stimulated a discussion with an anaesthetist friend of mine. After some time, we concluded that the quantity used and the space in which it was released would actually have had the effects described in the book.

Mayo keeps the tension and pace high through the middle of the book but this drops dramatically in the final act and an unresolved plot thread is introduced to keep the reader interested. In an attempt to spin Itch out into a multi-book saga, this patience remains frustratingly unrewarded.

The book is pitched well to readers from age 10 to 13. John Greenough, a student of mine, reported that he found the book exciting and that it stimulated him to find out more about many of the concepts presented: "I loved the new ideas, such as the island of stability and I was left with the urge to find out if it was true. [The author's notes were] very clever and informative in an informal and easy-toread way."

For those patient enough to wait for the story to begin, it's a really enjoyable read. There's an appropriate level of threat, a little bit of violence, a lot of vomiting and best of all enough science to get its readers asking questions and maybe even interested in some chemistry. That can't be a bad thing.

REVIEWED BY DECLAN FLEMING

Declan Fleming is a chemistry teacher in Bristol, UK. 